\title{
Editorial
}

\section{Perspectivas de inclusão em tempos de exclusão social: construindo pontes e mundos possíveis}

Com este número 38 da Paidéia: Cadernos de Psicologia e Educação completamos o volume 17 com a sensação não apenas do dever cumprido, como também de que se consuma uma importante etapa de transição que estamos administrando, desde a incorporação da revista à biblioteca eletrônica virtual SciELO (www.scielo.br).

Estamos disponibilizando à comunidade científica uma coletânea de trabalhos cujo valor e consistência poderão, a partir de agora, ser aquilatados por nossos pares.

Uma visão panorâmica do acervo de trabalhos reunidos sugere, subjacente à aparente heterogeneidade de objetos e referenciais teóricometodológicos privilegiados pelos autores, alguns traços convergentes. Uma das preocupações recorrentes que atravessa vários dos artigos que encartam o presente número diz respeito à questão da inclusão, cuja relevância tem sido maximizada em tempos de acelerados processos de exclusão social, catalisados pela transição para o capitalismo globalizado.

Vivemos um momento de exaustão dos modelos tradicionais de organizar a produção da vida. Diante das reiteradas crises que desafiam o futuro da humanidade já se faz sentir um clamor por transformações em direção a formas sustentáveis e mais justas de gerir os recursos e distribuir as riquezas produzidas pela coletividade. As mudanças que sacodem a sociedade globalizada têm dado visibilidade à busca de novos modelos e engendrado novas formas de subjetivação. Todavia, o redirecionamento das prioridades sociais para o âmbito comunitário exige a rotação de perspectiva do individual para o coletivo, a valorização da integração de múltiplos saberes e a incorporação da pluralidade de pontos de vista. É preciso que essas discussões permeiem a formação acadêmica e ganhem a agenda pública, de modo a fomentar reflexões que nos permitam construir respostas à altura dos desafios que enfrentamos no mundo contemporâneo. Só assim poderemos transformar as crises em oportunidades de crescimento e a falta de perspectiva em esperança de resolução.

Nesse contexto de transição e de quebra de paradigmas, a inclusão é o encontro dos indivíduos naquilo que eles possuem de comum. Quando reconhecemos e respeitamos as diferenças, pode ser um encontro enriquecedor e frutífero para todos. Podemos, assim, ser parceiros nos sonhos, solidários nos projetos de mudança, confiantes na possibilidade de reinventar permanentemente a sociedade democrática. Assim, possibilitaremos uma vida mais rica e mais plena para todos.

No limiar de sua maturidade, este periódico está consolidado como espaço aglutinador de saberes contemporâneos porque entende que é necessário acolher a diversidade e aprender a pensar em termos de multiplicidades e simultaneidades. $\mathrm{Na}$ área da Psicologia e da Educação temos produzido conhecimento de primeira linha. Desse modo, a Universidade se afirma não apenas como espaço de transmissão, mas, sobretudo, de produção e socialização do saber, honrando seu compromisso de universalização dos bens culturais gerados pelo corpo coletivo. Mas nesse domicílio de páginas também compartilhamos inquietações e refletimos criticamente sobre os caminhos que aí estão. Incluímos nesse debate o que somos e projetamos o que queremos ser. Afinal, de certo modo aquilo que somos depende daquilo que desejamos ser.

Imbuídos desse espírito crítico-reflexivo, seguem-se 11 artigos, divididos em seção teórica, composta por quatro trabalhos, e a de pesquisa empírica, com sete artigos.

Dando início à seção dedicada às Pesquisas Teóricas, o estudo de Sergio Fernandes Senna Pires e Angela Uchoa Branco, da Universidade de Brasília, intitulado Protagonismo infantil: co-construindo significados em meio às práticas sociais, apresenta um instigante painel sócio-histórico-cultural sobre o protagonismo da criança. Ao colocar em perspectiva as concepções de protagonismo infantil, os auto- 
res dão visibilidade à construção social do conceito de infância e propõem repensar as possibilidades de participação das crianças na sociedade, em termos das práticas sociais relacionadas à institucionalização da infância. $\mathrm{O}$ artigo traz contribuições valiosas que nos permitem construir pontes para superar barreiras e diminuir a distância entre o mundo infantil e o mundo adulto.

Enveredando também pelos caminhos do indivíduo em formação face ao processo educativo, o próximo artigo, da autoria de Roseli Fischmann, da Universidade de São Paulo, São Paulo, que tem por título Injustiça, autonomia moral e organização escolar: análise exploratória de relações, tematiza a questão do solapamento da autonomia moral nas organizações, em especial na escola, e seus reflexos contundentes na construção de uma sociedade democrática. $\mathrm{O}$ artigo coloca em relevo a relação entre diversidade e direitos humanos na perspectiva de Bobbio, além de encaminhar a discussão no sentido de tecer pontes teóricas que permitem à autora articular as relações entre as organizações e seus membros, assim como entre processos e práticas organizacionais, destacando a capacidade de resistência e autonomia. A autora busca explorar possibilidades para a educação frente a essas relações, estimulando reflexões sobre práticas inclusivas das assim chamadas minorias.

O próximo artigo, de autoria de Danilo Saretta Verissimo e Reinaldo Furlan, da Universidade de São Paulo, Ribeirão Preto, intitulado Entre a Filosofia e a Ciência: Merleau-Ponty e a Psicologia, parte de uma perspectiva de quem se posiciona em um lugar fronteiriço, ou de um entre-lugares. A tentativa, nesse caso, é construir pontes entre o conhecimento filosófico e a ciência, utilizando como plataforma para essa compreensão o pensamento fenomenológico de Merleau-Ponty, tal como é apropriado pela Psicologia. Segundo os autores do estudo, o diálogo estabelecido por Merleau-Ponty com a Psicologia permite pensar aspectos epistemológicos fundamentais do saber psicológico.

O próximo artigo, Concepções pedagógicas e método de ensino: O manual didático Processologia na Escola Primária, de Vera Teresa Valdemarin e Daniela Gonçalves do Santos Campos, da Universidade Estadual Paulista Júlio de Mesquita Filho, Araraquara, traz uma análise minuciosa de um manual didático publicado em 1956, com o objetivo de compreender o processo de incorporação das concepções pedagógicas da Escola Nova nas prescrições para a prática pedagógica. As autoras depreenderam de sua análise um processo de inovação e permanência na educação, que permite demarcar as influências de tradições já estabelecidas e a relevância dos textos didáticos como instrumentos mediadores para a difusão e circulação de idéias.

Abrindo o bloco de Pesquisas Empíricas, o artigo Adolescent risk-taking: comparison between adolescents' and adults' opinion, de autoria de Neslihan Güney Karaman e Figen Çok, da Universidade de Ankara, Turquia, apresenta uma contribuição importante à questão dos comportamentos de risco entre adolescentes. Em busca de pontes que permitam aproximar o conhecimento sobre adolescentes e adultos, os autores examinaram as concepções sobre comportamentos de risco e encontraram diferenças significativas nas percepções dos dois grupos.

O próximo artigo, da autoria de Nancy Capretz Batista da Silva, Thiago Bomfim, Nilceu Pfitter Cardozo, Maria Aparecida Paiva Franco e Susi Lippi Marques, da Universidade Federal de São Carlos, intitula-se Proposta de instrumento para avaliar conhecimento de jovens sobre métodos contraceptivos. A temática abordada é relevante e oportuna para o âmbito da saúde pública, tendo em vista os dados alarmantes sobre as ocorrências de gravidez na adolescência. $\mathrm{O}$ estudo avaliou a eficácia de um questionário construído para medir o conhecimento de estudantes do nível médio sobre métodos contraceptivos. $\mathrm{O}$ instrumento apresentou propriedades psicométricas adequadas, o que referenda sua aplicação enquanto recurso técnico de avaliação. Segundo os autores, esse instrumento poderá servir como apoio para a elaboração de intervenções preventivas que almejem promover maior conhecimento sobre métodos contraceptivos, sexo seguro e menores índices de gravidez na adolescência.

O artigo Escolha de parceiros afetivos: influência das seqüelas de fissura labiopalatal, da autoria de Fernanda Renda Brasil e Liliam D’Aquino Tavano da Universidade de São Paulo, Bauru, e de 
Sandro Caramaschi e Olga Maria Piazentin Rolim Rodrigues da Universidade Estadual Paulista Júlio de Mesquita Filho, Bauru, aborda uma questão crucial no processo de inclusão de jovens com esse tipo de problema. Os autores compararam um grupo de adolescentes com fissura na tarefa desenvolvimental de busca de parceiros afetivos, buscando elucidar os critérios privilegiados para essa seleção. Os resultados contribuem para enriquecer a compreensão das especificidades do universo afetivo dos adolescentes com fissura labiopalatal.

O artigo Práticas avaliativas no ensino fundamental e cultura escolar, de Ana Raquel Lucato Cianflone e Érika Natacha Fernandes de Andrade, da Universidade de São Paulo, Ribeirão Preto, abor$\mathrm{da}$ as práticas avaliativas que configuram a cultura $\mathrm{e}$ o ethos escolares e como esses valores fundamentam e orientam o trabalho pedagógico. O estudo abordou professores, equipe pedagógica e direção no contexto de três escolas de ensino fundamental da rede estadual paulista. As autoras apresentam conclusões que permitem compreender os movimentos de resistência e ajustamento às novas medidas introduzidas pela Lei de Diretrizes e Bases da Educação Nacional, desvelando a precariedade na formalização dos processos de avaliação. Esse estudo se mostra bastante oportuno nesses tempos de exclusão social, ao investigar o regime de progressão continuada, um dispositivo que visa contribuir com o processo de inclusão social na educação básica.

No artigo $O$ estímulo à criatividade em cursos de licenciatura, Rejane Arruda Ribeiro e Denise de Souza Fleith, da Universidade de Brasília, examinaram a percepção de 82 professores universitários de cursos de licenciatura a respeito de suas práticas docentes. Mais especificamente, as autoras buscaram delimitar em que essas práticas favorecem ou restringem o desenvolvimento da criatividade do aluno, na perspectiva dos professores. A investigação abrangeu ainda a percepção de 1396 estudantes acerca dessas práticas docentes. Os resultados permitiram aproximar e comparar as percepções de professores e estudantes, indicando que a visão de professores acerca das práticas docentes foi mais favorável do que a dos alunos. Para os autores do estudo, o conhecimento das barreiras ao estímulo da criatividade pessoal representa contribuição importante para as práticas docentes no ensino superior, especialmente no domínio dos cursos de licenciatura.

No artigo Representações sociais da depressão no contexto escolar, Karla Carolina Silveira Ribeiro, Josevânia da Silva Cruz de Oliveira, Maria da Penha de Lima Coutinho, da Universidade Federal da Paraíba, e Ludgleydson Fernandes de Araújo, da Universidade Federal da Piauí, buscaram apreender as representações sociais da depressão elaboradas por crianças de escola pública. O estudo apresenta uma contribuição relevante à área, ao evidenciar que a depressão está associada a fatores psicossociais relacionados a vivências de solidão, desamparo, isolamento e rejeição social. Os autores concluem que, nas instituições de ensino, há necessidade de práticas preventivas e educacionais que promovam uma melhor qualidade de vida das crianças.

$\mathrm{O}$ artigo Desenvolvimento percepto-motor em crianças abrigadas e não abrigadas, de Adriana Cristina Boulhoça Suehiro, Fabián Javier Marín Rueda, da Universidade São Francisco, e Marlene Alves da Silva, da Faculdade de Tecnologia e Ciências, Vitória da Conquista, explorou possíveis diferenças no desempenho em um teste de percepção viso-motora entre crianças abrigadas e não abrigadas. Os resultados sistematizados indicaram que as crianças não abrigadas apresentaram um desempenho significativamente superior ao das abrigadas. Segundo os autores, o trabalho é inovador porque utiliza um sistema novo de análise de um instrumento de avaliação psicológica aplicado extensamente no contexto brasileiro.

A resenha Educação de surdos e educação inclusiva: reflexões sobre a aquisição (ou não) da língua brasileira de sinais, elaborada por Diléia Aparecida Martins, da Pontifícia Universidade Católica de Campinas, completa a relação de contribuições do presente número da revista. Nessa apreciação do livro "Educação de surdos: Pontos e contrapontos", de autoria de Regina Maria Souza e Núria Silvestre e organizado por Valeria Amorim Arantes, são focalizados os aspectos principais sobre essa obra extremamente oportuna, tendo em vista o debate contemporâneo sobre a inclusão de pessoas com necessidades especiais. 
Este número da Paidéia se encerra como os demais, com Notícias de Congressos, nominata de consultores ad hoc de 2007 e as Normas de Publicação.

Cabe ao Editor zelar pelo espaço valioso de disseminação do saber científico que uma revista do porte da Paidéia representa no cenário nacional. Mas executar essa missão seria de todo impraticável sem a colaboração de todos aqueles que, com seu trabalho incansável, colaboram diariamente para sustentar essa produção. Em primeiro lugar, os autores que nos confiam os seus manuscritos, certos de que receberão um julgamento imparcial de um corpo editorial criterioso, respaldado por uma assessoria altamente qualificada. Nesse sentido, também os consultores ad hoc devem ser lembrados, porque de sua pontualidade e disponibilidade de compartilhar seus conhecimentos especializados depende a manutenção do fluxo de manuscritos.

O conhecimento científico depende, visceralmente, de um acompanhamento rigoroso, por meio de aperfeiçoamento de mecanismos de aferição baseado em indicadores que permitam o monitoramento e a avaliação sistemática daquilo que é produzido. Esse é o diferencial do saber científico. Nessa direção, é preciso deixar consignada uma nota de agradecimento a todos os colegas que se dispuseram a colaborar com o processo de peer review durante o ano de 2007, cumprindo prazos freqüentemente exígüos para que pudéssemos agilizar o processo editorial.

O trio composto pelos Editores Assistentes também merecem ser louvados pelo modo ordenado e harmônico com que têm se desincumbido de suas inúmeras atribuições na partilha de responsabilidades.

A tramitação editorial não teria sido tão eficiente não fosse o trabalho brilhante de nosso assistente técnico-acadêmico, assim como de nosso diagramador. É preciso mencionar ainda a disposição da Coordenação do Programa de Pós-graduação em Psicologia da FFCLRP-USP em apoiar a revista, disponibilizando recursos para o aprimoramento da qualidade formal dos manuscritos.

Finalmente, é preciso reconhecer o empenho da chefia do Departamento de Psicologia e Educação da FFCLRP-USP em fornecer as instalações, recursos humanos e insumos materiais que a Paidéia necessita para o bom desempenho de sua missão.
Também deve ser devidamente evocado e reconhecido em seu mérito o fomento financeiro que recebemos do Sistema Integrado de Bibliotecas - SIBI da Universidade de São Paulo e do Conselho Nacional de Desenvolvimento Científico e Tecnológico CNPq. A propósito, a Paidéia tem sido regularmente apoiada pelo Programa de Apoio às Publicações Periódicas da Universidade de São Paulo. Afinal, manter, consolidar e ampliar essas conquistas é um esforço que exige investimentos e um montante considerável de recursos.

Aos leitores, consumidores dos resultados de pesquisa de boa cepa, dedicamos uma última mensagem. Esperamos conseguir envolvê-los no mesmo entusiasmo e espírito de luta que nos têm movido ultimamente, encorajando-nos a perseverar no imenso esforço coletivo que se exige de quem se propõe a sustentar uma revista com periodicidade quadrimestral. Esse é o sentido maior da teia do conhecimento: que aquilo que se produz por inúmeras mãos e mentes possa ser finalmente apropriado, de modo a se tornar um conhecimento de todos.

Manoel Antônio dos Santos 